\title{
T-cell immunoglobulin mucin-3 expression in invasive ductal breast carcinoma: Clinicopathological correlations and association with tumor infiltration by cytotoxic lymphocytes
}

\author{
HUAN ZHANG ${ }^{1}$, RONG XIANG $^{2}$, BIN WU $^{3}$, JINLONG LI $^{1}$ and GUILIN LUO ${ }^{1}$ \\ ${ }^{1}$ Department of General Surgery, The Fourth People's Hospital of Sichuan, Chengdu, Sichuan 610000; \\ ${ }^{2}$ Department of Medicine, Nan Kai University, Tianjin 300071; ${ }^{3}$ Department of Breast Surgery, \\ Southwest Medical University Affiliated Hospital, Luzhou, Sichuan 646000, P.R. China
}

Received September 16, 2016; Accepted March 8, 2017

DOI: $10.3892 / \mathrm{mco} .2017 .1360$

\begin{abstract}
As a negative regulatory molecule, T-cell immunoglobulin and mucin domain-3 (Tim-3) is closely associated with tumor immunological tolerance. The aim of this study was to investigate Tim-3 expression in invasive ductal breast cancer (IDC), its effect on clinicopathological parameters and its association with cytotoxic lymphocyte infiltration. Tim-3 protein expression was measured in 150 paraffin-embedded IDC specimens and 100 paired normal breast tissue specimens by immunohistochemistry. It was demonstrated that the infiltration of the tumor by $\mathrm{CD} 8^{+} \mathrm{T}$ cells was significantly higher compared with that of normal tissue, and the Tim-3 expression on $\mathrm{CD}^{+} \mathrm{T}$ cells was higher in IDC tissue compared with that in normal tissue; the differences were statistically significant (both P-values=0.000). The median expression level of Tim-3 on tumor cells was significantly associated with clinicopathological parameters such as age, axillary lymph node metastasis and TNM stage $(\mathrm{P}=0.015,0.001$ and 0.027 , respectively). The expression of Tim- 3 on $\mathrm{CD}^{+} \mathrm{T}$ cells was correlated with lymph node metastasis, World Health Organization (WHO) grade and molecular classification $(\mathrm{P}=0.000,0.004$ and 0.000 , respectively). Additionally, the number of tumor-infiltrating $\mathrm{CD} 8^{+} \mathrm{T}$ cells was associated with primary tumor size, lymph node metastasis, WHO grade, Ki-67 and molecular classification $(\mathrm{P}=0.017,0.002,0.007,0.003$ and 0.000 , respectively). Thus, Tim-3 may promote the development and progression of breast cancer and affect the tumor microenvironment; thus, it may be used as an independent prognostic factor for IDC patients.
\end{abstract}

Correspondence to: Dr Jinglong Li, Department of General Surgery, The Fourth People's Hospital of Sichuan, East 57th Street, Jinjiang, Chengdu, Sichuan 610000, P.R. China

E-mail: 825895181@qq.com

Key words: invasive ductal breast cancer, T-cell immunoglobulin and mucin domain-3, tumor-infiltrating cytotoxic lymphocyte, immune regulation, tumor invasion and metastasis, immunohistochemical

\section{Introduction}

Breast cancer is a major health concern worldwide and the most common type of cancer among women (1), with a reported 458,000 deaths annually, making it the most common cause of cancer-related mortality among women in developed as well as developing countries (2). Therefore, there is an urgent need for novel biomarkers for the prognosis and effective treatment of breast cancer. The T-cell immunoglobulin and mucin domain (TIM) gene family was positionally cloned in 2001 from within the T-cell and airway phenotype regulator locus as novel allergy and asthma susceptibility genes (3). The TIM gene family consists of eight members (TIM-1-8) on mouse chromosome 11B1.1, and three members (TIM-1, TIM-3 and TIM-4) on human chromosome 5q33.2, a chromosomal region that has been repeatedly associated with asthma, allergy and autoimmunity (4).

Tim-3 was found to be particularly expressed in $\mathrm{T}$ helper type 1 (Th1) cells, CD8 $8^{+} \mathrm{T}$ cells and Th17 cells. At present, Tim-3 expression may be found in innate immune cells, including natural killer (NK) cells, dendritic cells (DCs), monocytes, mast cells and other lymphocyte subpopulations (5-8).

In recent years, Tim- 3 has been considered to be a negative regulatory molecule, which plays a crucial role in antitumor immunity. However, the mechanism underlying its antitumor properties remains unknown. The aim of this study was to investigate the expression of Tim-3 in 150 invasive ductal breast cancer (IDC) and 100 normal breast tissue samples by immunohistochemistry and determine the expression of Tim-3 in breast cancer tissue and its association with clinicopathological parameters and cytotoxic lymphocyte (CTL) infiltration.

\section{Patients and methods}

Patient selection. A total of 150 breast cancer tissue specimens were collected from female patients at the Department of Breast Surgery of the Southwest Medical University Affiliated Hospital (Sichuan, China) between April, 2013 and May, 2014; all the cases were pathologically diagnosed postoperatively. 
Following selection of the paraffin blocks, $4-\mu \mathrm{m}$ sections were prepared, stained with hematoxylin and eosin (HE), and the diagnosis was confirmed by two pathologists. Sections with inflammation, hemorrhage and incisional biopsies with insufficient tissue were excluded from the study. Clinical information, including age, primary tumor size, axillary lymph node metastasis and TNM stage, World Health Organization (WHO) grade, Ki-67, molecular classification and location of the lesion, was extracted from patient files and recorded in tables. The median age of the patients was 49.6 years (range, 33-68 years). Patients without any complications did not receive chemotherapy or other therapies prior to surgery. Furthermore, 100 pathologically confirmed normal breast tissue or benign lesion samples were also obtained, located at a distance $3.0-5.0 \mathrm{~cm}$ from the tumor. All the participants provided written informed consent and the study protocol was approved by the Ethics Committee of the Affiliated Hospital of Xinan Medical University. The study was conducted over a period of 6 months.

Reagents and instruments. Rabbit anti-human Tim-3 polyclonal antibody (dilution, 1:500; catalog no., 185703; Abcam, Cambridge, UK); murine monoclonal anti-human CD8 antibody (dilution 1:500, GM710301, Gene Biology Company, Shanghai, China), $10 \%$ neutral buffered formalin, xylene, serial concentrations of ethanol, phosphate-buffered solution (PBS), 3\% $\mathrm{H}_{2} \mathrm{O}_{2}$ and diaminobenzidine (DAB) (all from Jinshan Chemical Reagent Company, Chengdu, China).

Immunohistochemistry. To quantify Tim-3 cells in large numbers of patients, paraffin-embedded IDC samples were processed for immunohistochemistry. The specimens were fixed in 10\% neutral buffered formalin, embedded in paraffin and cut into $4-\mu \mathrm{m}$ serial sections. Paraffin-embedded tissues were dewaxed in xylene, rehydrated by serial concentrations of ethanol and rinsed in PBS, followed by treatment with 3\% $\mathrm{H}_{2} \mathrm{O}_{2}$ to block endogenous peroxidase. Following heating in a microwave at $750 \mathrm{~W}$ for $15 \mathrm{~min}$ to retrieve the tissue antigen, the sections were incubated with $10 \%$ normal goat serum at room temperature for 10 min to block non-specific reactions. This was followed by washing with PBS and incubation with polyclonal rabbit anti-human Tim-3 antibody (dilution, 1:500, clone 185703, IgG2a; Abcam), murine monoclonal anti-human CD8 antibody, for $12 \mathrm{~h}$ at $4^{\circ} \mathrm{C}$, and with horseradish peroxidase-conjugated goat anti-rat $\mathrm{IgG}$ (dilution, 1:500; GM710301; Gene Biology Company, Shanghai, China). Following washing with PBS, the sections were developed in DAB substrate. The sections were then counterstained with hematoxylin for $2 \mathrm{~min}$ and dehydrated in ethanol and xylene prior to mounting on slides. The sections were subjected to EnVision immunohistochemical staining. PBS instead of primary antibodies was used as negative control. Visualization was achieved with ABC-Elite Reagent (Sigma, St. Louis, MO, USA). The sections were counterstained with Mayer's hematoxylin (Sigma). The nuclei were stained with $1 \%$ ammonium hydroxide. The number of Tim-3 cells was counted in five fields at a magnification of $\mathrm{x} 400$.

Statistical analysis. All the data were analyzed with the SPSS software package, version 17.0 (SPSS Inc., Chicago, IL,
USA). Due to the non-normal distribution, the Mann-Whitney U-test was used for comparison between groups. Independent samples t-test was used for the comparison of two means; the Chi-squared test was used for rate comparison. P-values $<0.05$ were considered to indicate statistically significant differences.

\section{Results}

Expression of Tim-3 in the tissue of invasive breast carcinoma and normal breast tissue. Tim-3 was found to be expressed on the surface of the tumor cells (Fig. 1) and $\mathrm{CD} 8^{+} \mathrm{T}$ cells (Fig. 2). Tim-3 expression on IDC cells (98\%) was significantly higher compared with that in normal breast tissue $\left(13 \% ; \chi^{2}=0.195\right.$, $\mathrm{P}=0.000$ ). Similarly, the expression of Tim -3 on $\mathrm{CD} 8^{+} \mathrm{T}$ cells in IDC tissue $(90 \%)$ was also significantly increased compared with that in normal breast tissue $\left(23 \% ; \chi^{2}=11.11, \mathrm{P}=0.000\right.$; Table I).

Association between Tim-3 expression and clinicopathological characteristics in IDC patients. The expression of Tim-3 on tumor cells was significantly associated with clinicopathological characteristics, such as gender, age, lymph node metastasis and TNM stage ( $\mathrm{P}=0.015,0.001$ and 0.027 , respectively). Our study indicated that the median expression level of Tim-3 on $\mathrm{CD} 8^{+} \mathrm{T}$ cells was significantly associated with clinicopathological parameters such as lymph node metastasis, TNM stage, WHO grade and molecular classification $(\mathrm{P}=0.000,0.004$, 0.009 and 0.000 , respectively), whereas it was not correlated with other clinicopathological parameters (all P-values $>0.05$; Table II).

Association between Tim-3 expression and the degree of $\mathrm{CD}^{+} 8$ T-cell infiltration. The degree of $\mathrm{CD} 8^{+} \mathrm{T}$-cell infiltration in IDC (Fig. 3) was higher compared with that in normal breast tissue (Fig. 4). Further analysis revealed that the degree of $\mathrm{CD} 8^{+}$ T-cell infiltration was significantly correlated with primary tumor size, lymph node metastasis, WHO grade, Ki-67 and molecular classification $(\mathrm{P}=0.017,0.002,0.007,0.003$ and 0.000 , respectively), whereas it was not correlated with other clinicopathological parameters (all P-values $>0.05$; Table III).

Furthermore, by evaluating the abovementioned parameters that were statistically significant by logistic multifactor regression analysis, axillary lymph node metastasis, WHO grade, Ki-67 and molecular classification were found to significantly affect the extent of the tumor infiltration by CTLs (all P-values $<0.05$; Table IV).

\section{Discussion}

Co-opted immune checkpoint pathways are likely involved in the mechanism underlying tumor immune suppression. Tim-3 is a newly confirmed molecule with an important immunological function in several physiological and pathological processes.

Tim-3 was initially found to be selectively expressed on terminally differentiated interferon $\gamma$-producing $\mathrm{CD} 4^{+} \mathrm{Th} 1$ cells and $\mathrm{CD}^{+}$cytotoxic T cells $(9,10)$, as well as on Th17 cells, DCs, monocytes, regulatory T cells (Tregs), mast cells, NK cells and tumor-infiltrating lymphocytes. It is also expressed on tumor cells, such as melanoma, squamous cell carcinoma, 
Table I. Expression of Tim-3 on breast tissue cells and on CTLs in IDC and normal breast or benign lesions.

$\begin{array}{cc}\begin{array}{c}\text { Expression of Tim-3 on } \\ \text { breast tissue cells }\end{array} & \text { Expression of Tim-3 } \\ \text { on CTLs }\end{array}$

\begin{tabular}{lccccc}
\cline { 3 - 5 } Variables & Patient no. & High $(\mathrm{n})$ & Rate $(\%)$ & High $(\mathrm{n})$ & Rate $(\%)$ \\
\hline IDC & 150 & 147 & 98 & 135 & 90 \\
Normal breast/benign lesions & 100 & 13 & 13 & 23 & 23 \\
$\chi^{2}$ & & & 0.195 & & 11.11 \\
P-value & & & 0.000 & & 0.000 \\
\hline
\end{tabular}

Tim-3, T-cell immunoglobulin and mucin domain-3; CTL, cytotoxic lymphocyte; IDC, invasive ductal carcinoma.

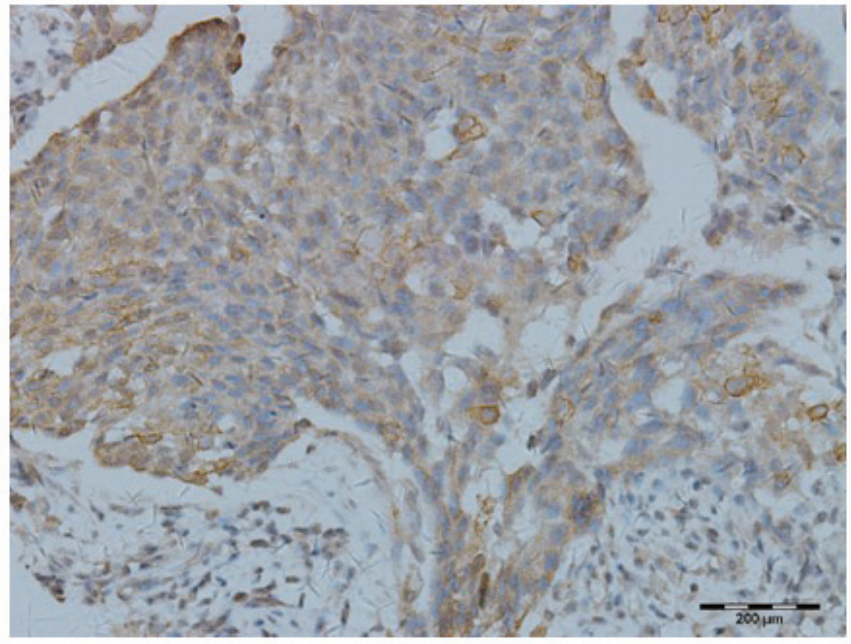

Figure 1. Photomicrograph showing high expression of Tim-3 on invasive ductal breast carcinoma cells (immunohistochemical staining; original magnification, x400). Tim-3, T-cell immunoglobulin and mucin domain-3.

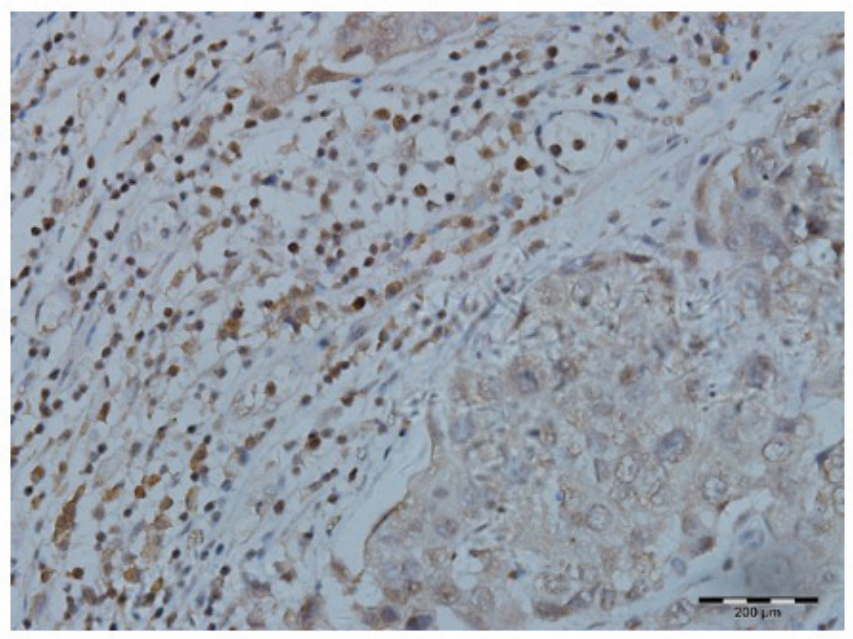

Figure 2. Photomicrograph of a section showing high expression of Tim-3 on the cytotoxic lymphocytes infiltrating invasive ductal breast carcinoma (immunohistochemical staining; original magnification, x400). Tim-3, T-cell immunoglobulin and mucin domain-3.

gastric cancer and non-small-cell lung cancer cells, but not on CD4 ${ }^{+}$Th2 cells (10-18).

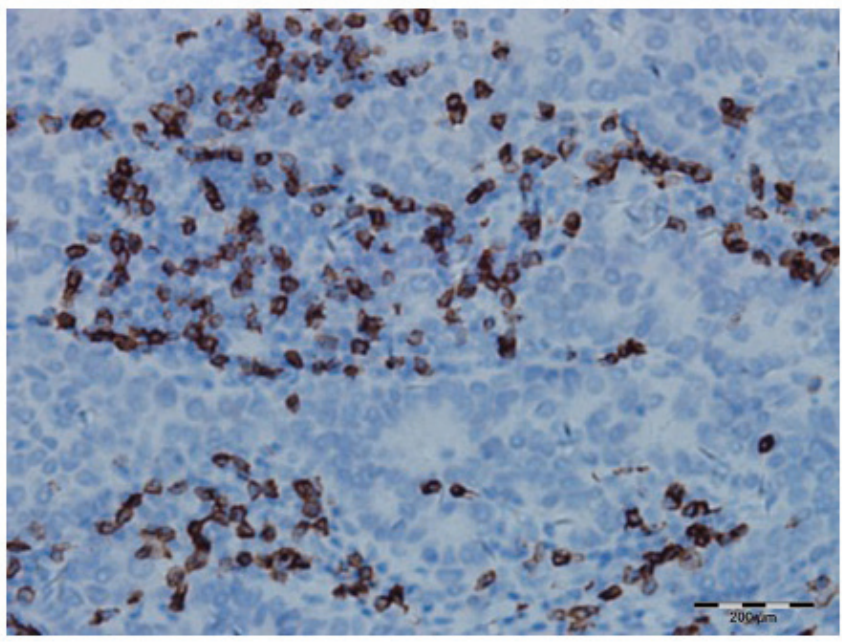

Figure 3. Photomicrograph of a section showing the extensive infiltration by $\mathrm{CD}^{+} \mathrm{T}$-cells in invasive ductal breast carcinoma tissue (immunohistochemical staining; original magnification, $\mathrm{x} 200$ ).

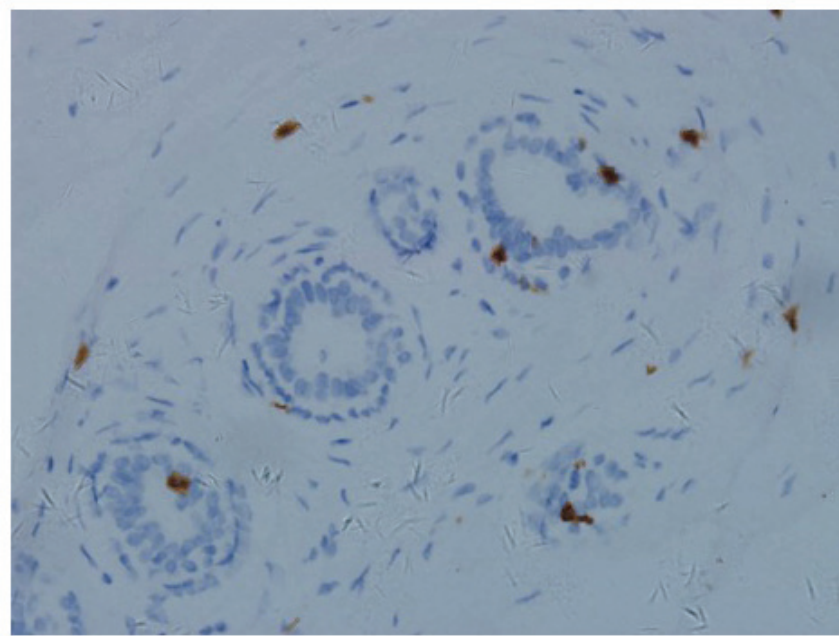

Figure 4. Photomicrograph of a section showing limited infiltration by CD8 $8^{+}$ T-cells in normal breast tissue (immunohistochemical staining; original magnification, $\mathrm{x} 200$ ).

Previous studies suggested that Tim-3 may modulate the immune response of Th1 cells and regulate cell immune 
Table II. Association between the expression of Tim-3 and the clinicopathological characteristics of patients with breastinfiltrating ductal carcinoma.

Tim-3 expression

\begin{tabular}{|c|c|c|c|c|c|c|c|}
\hline \multirow[b]{3}{*}{ Variables } & \multirow[b]{3}{*}{ Patient no. $(n=150)$} & \multirow{2}{*}{\multicolumn{3}{|c|}{ On tumor cells }} & & & \\
\hline & & & & & \multicolumn{3}{|c|}{ On CTLs } \\
\hline & & Low $(\%)$ & High (\%) & P-value & Low $(\%)$ & $\operatorname{High}(\%)$ & P-value \\
\hline Age, years & & & & 0.015 & & & 0.991 \\
\hline$<45$ & 48 & $27(56.25)$ & $21(43.75)$ & & $24(50.00)$ & $24(50.00)$ & \\
\hline$\geq 45$ & 102 & $36(35.29)$ & $66(64.71)$ & & $52(50.98)$ & $50(49.02)$ & \\
\hline Tumor size & & & & 0.422 & & & 0.114 \\
\hline $\mathrm{T} 1$ & 51 & $24(47.06)$ & $27(52.94)$ & & $31(60.78)$ & $20(39.21)$ & \\
\hline $\mathrm{T} 2$ & 36 & $15(41.67)$ & $21(58.33)$ & & $18(50.00)$ & $18(50.00)$ & \\
\hline $\mathrm{T} 3$ & 60 & $24(40.00)$ & $36(60.00)$ & & $27(45.00)$ & $33(55.00)$ & \\
\hline $\mathrm{T} 4$ & 3 & $0(0.00)$ & $3(100.00)$ & & $0(0.00)$ & $3(100.00)$ & \\
\hline Lymph node status & & & & 0.001 & & & 0.000 \\
\hline No & 42 & $21(50.00)$ & $21(50.00)$ & & $36(85.71)$ & $6(14.29)$ & \\
\hline $\mathrm{N} 1$ & 69 & $36(52.17)$ & $33(47.82)$ & & $28(40.58)$ & $41(59.42)$ & \\
\hline $\mathrm{N} 2$ & 24 & $3(12.50)$ & $21(87.50)$ & & $6(25.00)$ & $18(75.00)$ & \\
\hline N3 & 15 & $3(20.00)$ & $12(80.00)$ & & $6(40.00)$ & $9(60.00)$ & \\
\hline TNM stage & & & & 0.027 & & & 0.004 \\
\hline I & 18 & $12(66.67)$ & $6(33.33)$ & & $10(55.56)$ & $8(44.44)$ & \\
\hline II & 42 & $21(50.00)$ & $21(50.00)$ & & $30(71.43)$ & $12(28.57)$ & \\
\hline III & 60 & $18(30.00)$ & $42(70.00)$ & & $27(45.00)$ & $33(55.00)$ & \\
\hline IV & 30 & $12(40.00)$ & $18(60.00)$ & & $9(30.00)$ & $21(70.00)$ & \\
\hline WHO grade & & & & 0.536 & & & 0.009 \\
\hline I & 15 & $6(40.00)$ & $9(50.00)$ & & $3(20.00)$ & $12(80.00)$ & \\
\hline II & 99 & $39(39.39)$ & $60(60.61)$ & & $49(49.49)$ & $50(50.51)$ & \\
\hline III & 36 & $18(50.00)$ & $18(50.00)$ & & $24(66.67)$ & $12(33.33)$ & \\
\hline $\mathrm{Ki}-67, \%$ & & & & 0.630 & & & 0.512 \\
\hline$<14$ & 39 & $15(38.46)$ & $24(61.24)$ & & $18(46.15)$ & $21(53.85)$ & \\
\hline$\geq 14$ & 111 & $48(43.24)$ & $63(56.76)$ & & $58(52.25)$ & $53(47.75)$ & \\
\hline Molecular classification & & & & 0.314 & & & 0.000 \\
\hline Luminal A & 24 & $9(37.50)$ & $15(62.50)$ & & $15(62.50)$ & $9(37.50)$ & \\
\hline Luminal B & 60 & $30(50.00)$ & $30(50.00)$ & & $18(30.00)$ & $42(60.00)$ & \\
\hline HER2-overexpressing & 36 & $15(41.67)$ & $21(58.33)$ & & $19(52.78)$ & $17(47.22)$ & \\
\hline Basal-like & 30 & $9(30.00)$ & $21(70.00)$ & & $24(80.00)$ & $6(20.00)$ & \\
\hline
\end{tabular}

Tim-3, T-cell immunoglobulin and mucin domain-3; CTL, cytotoxic lymphocyte; TNM, tumor-node-metastasis; WHO, World Health Organization; HER2, human epidermal growth factor receptor 2.

tolerance $(19,20)$. Tim-3 has also drawn significant attention in autoimmune diseases, anaphylactic diseases, immune tolerance and antitumor immunity $(21,22)$. The Tim-3/galectin-9 pathway plays an important role in the suppressive tumor microenvironment (TME). In a variety of cancers, the overexpression of Tim-3 is associated with poor prognosis (9).

Tim-3 marks the most suppressed or dysfunctional population of $\mathrm{CD}^{+} \mathrm{T}$ cells in preclinical models of solid as well as hematological malignancies; thus, Tim-3 may be a key immune checkpoint in tumor-induced immune suppression $(18,23)$.

The Tim-3/galectin-9 pathway contributes to the TME in the human body and Tim-3 is also characterized as a key regulator of the dysfunctional $\mathrm{CD}^{+} \mathrm{T}$-cell phenotype $(18,24)$ early in the TME, where neoplastic growth is promoted via induction of $\mathrm{CD}^{+} \mathrm{T}$-cell dysfunctionality (25).

Several recent studies demonstrated that Tim-3 is highly expressed in a large number of tumor tissues types, including cervical cancer (15), gastric cancer (16), acute myeloid leukemia (23) lung cancer (25), ovarian cancer (26) and glioma (27). In this study, the Tim-3 expression on tumor cells and $\mathrm{CD}^{+} \mathrm{T}$ cells of IDC and normal breast tissues was investigated by immunohistochemistry. The expression of Tim-3 in IDC tissue was distinctly higher compared with that in normal breast tissue $(\mathrm{P}=0.000)$, which 
Table III. Association between expression of Tim-3 on CTLs and the clinicopathological parameters of breast infiltrating ductal carcinoma.

Expression of Tim-3 on CTLs

\begin{tabular}{|c|c|c|c|c|c|}
\hline & & & & & \\
\hline Variables & Patient no. $(n=150)$ & Low $(\%)$ & $\operatorname{High}(\%)$ & $\chi^{2}$ & P-value \\
\hline Age, years & & & & 3.160 & 0.075 \\
\hline$<45$ & 48 & $18(37.50)$ & $30(62.50)$ & & \\
\hline$\geq 45$ & 102 & $24(23.53)$ & $78(76.47)$ & & \\
\hline Tumor size & & & & 10.177 & 0.017 \\
\hline $\mathrm{T} 1$ & 51 & $15(29.41)$ & $36(70.59)$ & & \\
\hline $\mathrm{T} 2$ & 36 & $6(16.67)$ & $30(83.33)$ & & \\
\hline $\mathrm{T} 3$ & 60 & $18(30.00)$ & $42(70.00)$ & & \\
\hline $\mathrm{T} 4$ & 3 & $3(100.00)$ & $0(0.00)$ & & \\
\hline Lymph node status & & & & 14.482 & 0.002 \\
\hline N0 & 42 & $3(7.14)$ & 39 (92.87) & & \\
\hline N1 & 69 & $27(39.13)$ & $42(60.87)$ & & \\
\hline N2 & 24 & $6(25.00)$ & $18(75.00)$ & & \\
\hline N3 & 15 & $6(40.00)$ & $9(60.00)$ & & \\
\hline TNM stage & & & & 3.564 & 0.313 \\
\hline $\mathrm{I}$ & 18 & $3(16.67)$ & $15(83.33)$ & & \\
\hline II & 42 & $12(28.57)$ & $30(71.43)$ & & \\
\hline III & 60 & $15(25.00)$ & $45(75.00)$ & & \\
\hline IV & 30 & $12(40.00)$ & $18(60.00)$ & & \\
\hline WHO grade & & & & 9.939 & 0.007 \\
\hline $\mathrm{I}$ & 15 & $9(60.00)$ & $6(40.00)$ & & \\
\hline II & 99 & 27 (27.27) & $72(72.72)$ & & \\
\hline III & 36 & $6(16.67)$ & $30(83.33)$ & & \\
\hline Ki-67 & & & & 8.615 & 0.003 \\
\hline$<14 \%$ & 39 & $18(46.15)$ & $21(53.85)$ & & \\
\hline$\geq 14 \%$ & 111 & $24(21.62)$ & $87(78.38)$ & & \\
\hline Molecular classification & & & & 23.636 & 0.000 \\
\hline Luminal A & 24 & $9(37.50)$ & $15(62.50)$ & & \\
\hline Luminal B & 60 & $27(45.00)$ & $33(55.00)$ & & \\
\hline HER2-overexpressing & 36 & $6(16.67)$ & $30(83.33)$ & & \\
\hline Basal-like & 30 & $0(0.00)$ & $30100.00)$ & & \\
\hline Tim-3 expression on tumor & & & & 0.946 & 0.331 \\
\hline Low & 63 & $15(23.80)$ & $48(76.20)$ & & \\
\hline High & 87 & $27(31.03)$ & $60(68.97)$ & & \\
\hline
\end{tabular}

CTL, cytotoxic lymphocyte; TNM, tumor-node-metastasis; WHO, World Health Organization; HER2, human epidermal growth factor receptor 2; Tim-3, T-cell immunoglobulin and mucin domain-3.

suggested that Tim-3 was involved in the pathogenesis of breast cancer via its regulatory effect on various immune cells and tumor cells, indicating that Tim-3 may play an important role in tumorigenesis. The expression of Tim-3 on tumor cells may affect the malignant biological behavior of the tumor.

In the present study, we observed that the expression of Tim-3 in IDC was significantly associated with age $(\mathrm{P}<0.05)$, reflecting the decrease in the overall immune ability of the body with advancing age. The expression of the negative regulatory immune molecule Tim-3 on breast cancer cells was clearly increased.

Our test results also demonstrated that the strength of the Tim-3 expression on tumor cells exhibited an increasing trend with the increasing number of metastatic axillary lymph nodes and advanced pathological stage. Furthermore, the expression of Tim-3 on IDC cells was significantly correlated with local axillary lymph node metastasis and pathological stage $(\mathrm{P}<0.05)$, but the results of our study demonstrated that primary tumor size, WHO grade, Ki-67 and molecular classification of breast 
Table IV. Analysis of multiple factors affecting the infiltration degree by CTLs.

\begin{tabular}{|c|c|c|c|c|c|c|c|c|}
\hline \multirow[b]{2}{*}{ Variables } & \multirow[b]{2}{*}{ B } & \multirow[b]{2}{*}{ SE } & \multirow[b]{2}{*}{ Wald } & \multirow[b]{2}{*}{ df } & \multirow[b]{2}{*}{ Sig } & \multirow[b]{2}{*}{$\operatorname{Exp}(B)$} & \multicolumn{2}{|c|}{$\operatorname{Exp}(\mathrm{B}) \mathrm{CI} 95 \%$} \\
\hline & & & & & & & Upper limit & Lower limit \\
\hline Tumor size & -13.962 & 0.685 & 425.901 & 1 & 0.229 & 1.767 & 0.488 & 8.566 \\
\hline Lymph node status & -4.649 & 1.387 & 11.236 & 1 & 0.001 & 0.010 & 0.046 & 1.345 \\
\hline WHO grade & 0.576 & 1.137 & .257 & 1 & 0.002 & 1.779 & 0.023 & 0.665 \\
\hline Ki-67 & 1.240 & 0.860 & 39.34 & 1 & 0.038 & 3.456 & 1.020 & 29.720 \\
\hline Molecular classification & 16.910 & 985.39 & 0.000 & 1 & 0.000 & $2.200 \mathrm{E} 9$ & $7.140 \mathrm{E} 8$ & 4.791E10 \\
\hline Tim-3 expression on tumor & -0.983 & 0.640 & 2.359 & 1 & 0.125 & 0.374 & 1.07 & 1.312 \\
\hline
\end{tabular}

CTLs, cytotoxic lymphocytes; WHO, World Health Organization; SE, standard error; df, degree of freedom; CI, confidence interval.

IDC were not significantly associated with the expression of Tim-3 on tumor cells. The possible underlying mechanisms may be as follows: i) A large amount of Tim-3 on the tumor cell surface forms a 'shield' to protect Tim-3-positive tumor cells from the toxicity of immunological effector cells; however, the expression of negative immune regulatory factor Tim-3 does not affect the proliferation and differentiation of tumor cells. ii) In some cases, the size of the primary tumor is large at clinical diagnosis; thus, immune adjustment factors are no longer able to interfere with the growth of tumor cells, or there is a disproportional rate of tumor cell proliferation and immune clearance. iii) The experimental data may be insufficient; thus, larger samples are required to confirm the findings.

In nearly all previous studies, immune cells were identified by specific cluster of differentiation (CD) markers, following immunohistochemical staining of the slides. It is important to distinguish between different types of $\mathrm{T}$ lymphocytes, as they all have different functions in the TME.

$\mathrm{CD}^{+} \mathrm{T}$ cells play an important role in the TME. CTL is the main antitumor immune cell type, which may identify tumor antigens and eliminate tumor cells with one of two main mechanisms: i) The perforin pathway, or ii) the Fas/FasL-mediated apoptosis pathway. Fourcade et al (28) discovered that Tim-3 was expressed on NY-ESO-1-specific $\mathrm{CD}^{+} \mathrm{T}$ cells in patients with advanced melanoma. They found that the blockade of both the Tim-3 and programmed cell death protein-1 (PD-1) pathways may reverse tumor-induced T-cell exhaustion in patients with advanced melanoma. Our results suggested that the Tim-3 expression on $\mathrm{CD}^{+} \mathrm{T}$ cells was correlated with tumor invasion and TNM stage, which may be due to Tim-3-induced T-cell exhaustion, leading to tumor occurrence.

Our test data demonstrated that the expression of Tim-3 on tumor-infiltrating CTLs increased as axillary lymph node metastasis progressed. Lymph node metastasis and TNM stage, primary tumor size, WHO grade and molecular classification are significantly associated with the expression of Tim-3 on CTL cells $(\mathrm{P}<0.05)$.

This indicates that the expression of Tim-3 on CTLs may inhibit the tumor cell-killing function of CTLs. Even in the TME, CD8 ${ }^{+}$CTLs may transform into $\mathrm{CD} 8^{+}$Tregs, decreasing the tumor-infiltrating CTL immune surveillance, decreasing the local immune function and promoting the growth of tumor cells and metastasis.
The present study analyzed the association of tumor-infiltrating CTLs and the pathological characteristics of breast-infiltrating ductal carcinoma by single factor analysis of variance and demonstrated that primary tumor size, axillary lymph node metastasis, WHO grade, Ki-67 and molecular classification may statistically significantly affect the degree of tumor CTL infiltration $(\mathrm{P}<0.05)$.

Furthermore, the abovementioned statistically significant parameters were assessed by multiple logistic regression analysis and the results also demonstrated that axillary lymph node metastasis, WHO grade, Ki-67 and molecular classification significantly affect the extent of CTL infiltration of the tumor. The possible underlying mechanism may be as follows: i) High expression of the negative immunomodulatory molecule Tim-3 on tumor-infiltrating CTLs may result in immune malfunction; as the tumor grows, CD8 ${ }^{+}$CTLs may transform into $\mathrm{CD}^{+}$Tregs. ii) Low degree of CTL infiltration may lead to poor local immunity, which may contribute to tumor growth. iii) The lower the degree of tumor differentiation, the higher its antigenicity, which may cause a stronger local immune response.

In conclusion, Tim-3 is expressed in the majority of solid tumors and tumor-infiltrating CTLs. This finding suggests that Tim-3 participates in the immune escape through the following mechanisms: i) When it binds to its receptor, Tim-3 may induce T-cell apoptosis or immune incompetence; ii) a large amount of Tim-3 on the tumor cell surface may form a 'shield', which may protect Tim-3-positive tumor cells from toxic injury or elimination by CTLs; iii) Tim-3 positive cells may also affect T-cell secretion of negative cytokines or Treg coordination.

Sakuishi et al (18) reported that, in lymphocytes infiltrating solid tumors in mice, co-expression of Tim-3 and PD-1 may be detected. The multi-targeted therapy of Tim-3 and PD-1 has been highly effective in controlling tumor growth. Our study demonstrated that the expression of Tim-3 in breast cancer tissue was negatively correlated with certain clinicopathological parameters; however, the underlying mechanisms remain unclear. Therefore, further research on the multi-targeted therapy of Tim-3 and PD-1 for the treatment of breast cancer.

In conclusion, Tim-3 is highly expressed in breast IDC cells and tumo-infiltrating CTLs. The expression of Tim-3 exhibits a positive correlation with the malignant behavior 
of the tumor. The expression of Tim-3 on CTLs is negatively correlated with degree of CTL infiltration, and Tim-3 expression in breast cancer exerts a negative effect on immune regulation. The largest diameter of the primary tumor, the number of metastatic axillary lymph nodes, degree of tumor cell differentiation and molecular classification of breast cancer significantly afect the extent of the CTL infiltration of the tumor tissue.

\section{References}

1. Ferlay J, Shin HR, Bray F, Forman D, Mathers C and Parkin DM: Estimates of worldwide burden of cancer in 2008: GLOBOCAN 2008. Int J Cancer 127: 2893-2917, 2010.

2. Eccles SA, Aboagye EO, Ali S, Anderson AS, Armes J, Berditchevski F, Blaydes JP, Brennan K, Brown NJ, Bryant HE, et al: Critical research gaps and translational priorities for the successful prevention and treatment of breast cancer. Breast Cancer Res 15: R92, 2013.

3. McIntire JJ, Umetsu SE, Akbari O, Potter M, Kuchroo VK, Barsh GS, Freeman GJ, Umetsu DT and DeKruyff RH: Identification of Tapr (an airway hyperreactivity regulatory locus) and the linked Tim gene family. Nat Immunol 2: 1109-1116, 2001

4. McIntire JJ, Umetsu DT and DeKruyff RH: TIM-1, a novel allergy and asthma susceptibility gene. Springer Semin Immunopathol 25: 335-348, 2004.

5. Hastings WD, Anderson DE, Kassam N, Koguchi K, Greenfield EA, Kent SC, Zheng XX, Strom TB, Hafler DA and Kuchroo VK: TIM-3 is expressed on activated human CD4+ T cells and regulates Th1 and Th17 cytokines. Eur J Immunol 39: 2492-2501, 2009.

6. Anderson AC, Anderson DE, Bregoli L, Hastings WD, Kassam N, Lei C, Chandwaskar R, Karman J, Su EW, Hirashima M, et al: Promotion of tissue inflammation by the immune receptor Tim-3 expressed on innate immune cells. Science 318: 1141-1143, 2007.

7. Khademi M, Illés Z, Gielen AW, Marta M, Takazawa N, Baecher-Allan C, Brundin L, Hannerz J, Martin C, Harris RA, et al: T Cell Ig- and mucin-domain-containing molecule-3 (TIM-3) and TIM-1 molecules are differentially expressed on human Th1 and Th2 cells and in cerebrospinal fluid-derived mononuclear cells in multiple sclerosis. J Immunol 172: 7169-7176, 2004

8. Nakae S, Iikura M, Suto H, Akiba H, Umetsu DT, Dekruyff RH, Saito H and Galli SJ: TIM-1 and TIM-3 enhancement of Th2 cytokine production by mast cells. Blood 110: 2565-2568, 2007.

9. Anderson AC: Tim-3, a negative regulator of anti-tumor immunity. Curr Opin Immunol 24: 213-216, 2012.

10. Anderson AC, Anderson DE, Bregoli L, Hastings WD, Kassam N, Lei C, Chandwaskar R, Karman J, Su EW, Hirashima M, et al: Promotion of tissue inflammation by the immune receptor Tim-3 expressed on innate immune cells. Science 318: 1141-1143, 2007.

11. Ngiow SF, Teng MW and Smyth MJ: Prospects for TIM3-targeted antitumor immunotherapy. Cancer Res 71: 6567-6571, 2011.

12. Wiener Z, Kohalmi B, Pocza P, Jeager J, Tolgyesi G, Toth S, Gorbe E, Papp Z and Falus A: TIM-3 is expressed in melanoma cells and is upregulated in TGF-beta stimulated mast cells. J Invest Dermatol 127: 906-914, 2007.

13. Zhuang X, Zhang X, Xia X, Zhang C, Liang X, Gao L, Zhang X and Ma C: Ectopic expression of TIM-3 in lung cancers: A potential independent prognostic factor for patients with NSCLC. Am J Clin Pathol 137: 978-985, 2012.
14. Yan J, Zhang Y, Zhang JP, Liang J, Li L and Zheng L: Tim-3 expression defines regulatory $\mathrm{T}$ cells in human tumors. PLoS One 8: e58006, 2013.

15. Cao Y, Zhou X, Huang X, Li Q, Gao L, Jiang L, Huang M and Zhou J: Tim-3 expression in cervical cancer promotes tumor metastasis. PLoS One 8: e53834, 2013.

16. Jiang J, Jin MS, Kong F, Cao D, Ma HX, Jia Z, Wang YP, Suo J and Cao X: Decreased galectin-9 and increased Tim-3 expression are related to poor prognosis in gastric cancer. PLoS One 8: e81799, 2013.

17. Yang ZZ, Grote DM, Ziesmer SC, Niki T, Hirashima M, Novak AJ, Witzig TE and Ansell SM: IL-12 upregulates TIM-3 expression and induces $\mathrm{T}$ cell exhaustion in patients with follicular B cell non-Hodgkin lymphoma. J Clin Invest 122: 1271-1282, 2012.

18. Sakuishi K, Apetoh L, Sullivan JM, Blazar BR, Kuchroo VK and Anderson AC: Targeting Tim-3 and PD-1 pathways to reverse T cell exhaustion and restore anti-tumor immunity. J Exp Med 207: 2187-2194, 2010.

19. Sánchez-Fueyo A, Tian J, Picarella D, Domenig C, Zheng XX, Sabatos CA, Manlongat N, Bender O, Kamradt T, Kuchroo VK, et al: Tim-3 inhibits T helper type 1-mediated auto- and alloimmune responses and promotes immunological tolerance. Nat Immunol 4: 1093-1101, 2003.

20. Sabatos CA, Chakravarti S, Cha E, Schubart A, Sánchez-Fueyo A, Zheng XX, Coyle AJ, Strom TB, Freeman GJ and Kuchroo VK: Interaction of Tim-3 and Tim-3 ligand regulates T helper type 1 responses and induction of peripheral tolerance. Nat Immunol 4: 1102-1110, 2003.

21. Simmons WJ, Koneru M, Mohindru M, Thomas R, Cutro S, Singh P, Dekruyff RH, Inghirami G, Coyle AJ, Kim BS and Ponzio NM: Tim-3+ T-bet+ tumor-specific Th1 cells colocalize with and inhibit development and growth of murine neoplasms. J Immunol 174: 1405-1415, 2005.

22. Hu WK, Lu XX, Yang S, Xu GP, Lan F, Chen SX, Ni W, Xiong WN and Xiong SD: Expression of the Th1-specific cell-surface protein Tim-3 increases in a murine model of atopic asthma. J Asthma 46: 872-877, 2009.

23. Zhou Q, Munger ME, Veenstra RG, Weigel BJ, Hirashima M, Munn DH, Murphy WJ, Azuma M, Anderson AC, Kuchroo VK and Blazar BR: Coexpression of Tim-3 and PD-1 identifies a $\mathrm{CD} 8+\mathrm{T}$-cell exhaustion phenotype in mice with disseminated acute myelogenous leukemia. Blood 117: 4501-4510, 2011.

24. Takamura S, Tsuji-Kawahara S, Yagita H, Akiba H, Sakamoto M, Chikaishi T, Kato M and Miyazawa M: Premature terminal exhaustion of Friend virus-specific effector CD8+ T cells by rapid induction of multiple inhibitory receptors. J Immunol 184: 4696-4707, 2010

25. Gao X, Zhu Y, Li G, Huang H, Zhang G, Wang F, Sun J, Yang Q, Zhang $X$ and Lu B: TIM-3 expression characterizes regulatory T cells in tumor tissues and is associated with lung cancer progression. PLoS One 7: e30676, 2012.

26. Wu J, Liu C, Qian S and Hou H: The expression of Tim-3 in peripheral blood of ovarian cancer. DNA Cell Biol 32: 648-653, 2013.

27. Han S, Feng S, Xu L, Shi W, Wang X, Wang H, Yu C, Dong T, $\mathrm{Xu} \mathrm{M}$ and Liang G: Tim-3 on peripheral CD4+ and CD8+ T cells is involved in the development of glioma. DNA Cell Biol 33: 245-250, 2014.

28. Fourcade J, Sun Z, Benallaoua M, Guillaume P, Luescher IF, Sander C, Kirkwood JM, Kuchroo V and Zarour HM: Upregulation of Tim-3 and PD-1 expression is associated with tumor antigen-specific CD8+T cell dysfunction in melanoma patients. J Exp Med 207: 2175-2186, 2010. 